\title{
Distribution of Colloidal and Powdered Activated Carbon for the in Situ Treatment of Groundwater
}

\author{
Rick McGregor \\ In Situ Remediation Services Ltd., St George, Canada \\ Email: rickm@irsl.ca
}

How to cite this paper: McGregor, R. (2020) Distribution of Colloidal and Powdered Activated Carbon for the in Situ Treatment of Groundwater. Journal of Water Resource and Protection, 12, 10011018.

https://doi.org/10.4236/jwarp.2020.1212060

Received: September 18, 2020

Accepted: December 7, 2020

Published: December 10, 2020

Copyright () 2020 by author(s) and Scientific Research Publishing Inc. This work is licensed under the Creative Commons Attribution International License (CC BY 4.0).

http://creativecommons.org/licenses/by/4.0/ (c) (i) Open Access

\begin{abstract}
The use of in situ technologies for the treatment of groundwater containing various compounds of concern are widely accepted. These technologies include chemical reduction, chemical oxidation, anaerobic and aerobic bioremediation, and adsorption, among others. One requirement for the successful application of these technologies is the delivery of the remedial reagent(s) to the compounds of concern. A rapidly evolving in situ technology is the injection of adsorptive media such as activated carbon and ion-exchange resin including powdered or colloidal activated carbon. Activated carbon has a long-demonstrated history of effectiveness for the removal of various organic and inorganic compounds in above ground water treatment systems. However, due to constraints related to the particle size and physical properties of the activated carbon, the in situ application of activated carbon has been limited. Recent developments in the manufacturing of activated carbon have created a smaller particle size allowing activated carbon to be applied in situ. To evaluate if powdered and colloidal activated carbon can be effectively distributed in aquifers, the two types of carbon were injected using direct push technology adjacent to each other at four sites with varying geology. Evaluation of distribution was completed by sampling the aquifer prior to and post-injection for total organic carbon. The results of the studies indicated that both forms of activated carbon were effectively delivered to the targeted injection zones with both carbon types being detected at least seven meters away from the point of injection. The colloidal form of the activated carbon showed good distribution throughout the four targeted zones of injection with 93 percent of the samples collected having colloidal activated carbon present within them whereas the powdered activated carbon cells were more susceptible to aquifer heterogeneity with only 67 percent of the samples collected having activated carbon present. Preferential accumulation of activated carbon was
\end{abstract}


observed in high horizontal hydraulic conductivity seams, especially within the powdered activated carbon cells. These results suggested that the powdered form of activated carbon was more suspectable at the four sites to heterogeneity within the aquifer than the colloidal form of activated carbon. Sampling of monitoring well screens installed prior to the injection of the two forms of activated carbon showed preferential accumulation of powdered activated carbon within the sand pack, which could result in sampling bias.

\section{Keywords}

In situ Remediation, Groundwater, Colloidal, Powdered, Activated Carbon

\section{Introduction}

The use of in situ approaches to restore aquifers to their original or near-original conditions has increased within the past three decades, with the United States Environmental Protection Agency [1] reporting that up to 23 percent of decisions at Superfund sites used in situ remediation to remediate the compounds of concern at the sites. Various in situ approaches can be used to address the compounds of concern within the groundwater and soil, including in situ chemical oxidation (ISCO); in situ chemical reduction (ISCR); enhanced in situ bioremediation (EISB); thermal and adsorption. There are numerous reasons why in situ methods are chosen for application, including reduced remedial time frames and reduced costs. However, like most remedial technologies, sub-optimal performance can result when the technologies are applied at sites due to various reasons. Less than desired performance can happen, from unrealistic objectives; poor conceptual site models (CSMs); underestimation of contaminant mass; and most commonly inadequate distribution of the reagents being injected [2] [3]. For most in situ technologies to work, the remedial reagents being introduced into the subsurface need to contact the compounds of concern. A variety of methods have been developed and implemented over the past decades to aid in the improvement of delivery and distribution of remedial reagents including direct push technology (DPT); specialized injection well designs both vertically and horizontally; hydro and pneumatic fracturing; and various specialized injection tools. The monitoring of the distribution of the remedial reagents after injection is usually completed using indirect methods such as monitoring of pressures; flow rates, monitoring well observations for the presence of reagents; and monitoring of general chemical parameters such as $\mathrm{pH}$, oxidation-reduction potential (ORP). These monitoring parameters can be useful but rarely provide direct data on the distribution of the reagents within the targeted impacted zone themselves.

During the past decade, the injection of activated carbon has become more common. Activated carbon has a well-proven treatment record for various organic and inorganic compounds, including volatile organic compounds and pe- 
troleum hydrocarbons in above-ground treatment systems. Activated carbon relies on adsorption and absorption to remove the compounds of concern from the dissolved phase and therefore has a limited lifespan, which is dependent on the number of sites where the compounds of concern can be adsorbed. The rate of removal from solution depends on numerous factors including the chemical properties and concentrations of the compounds being removed. Other factors affecting removal efficiency include contact time between the compounds being removed and activated carbon as well as the type of activated carbon being employed. Secondary factors include the presence of competing compounds, the $\mathrm{pH}$ of the system and the ionic strength of the water. Typically activated carbon is used to treat water (surface or ground) in above-ground vessels where conditions such as flow rate, pressure, contact time, and water quality can be controlled. The use of activated carbon in in situ applications was limited due to its particle size (>1000 microns $(\mu \mathrm{m})$ ) which made injection difficult. Additionally, concerns over its lifespan were also raised as injected reagents ideally have lifespans that last years to decades. Developments related to the manufacturing of activated carbon resulted in smaller particle sizes for the activated carbon with powdered $(\sim 40$ to $100 \mu \mathrm{m})$ and colloidal $(<5 \mu \mathrm{m})$ forms being commercialized. With reduced particle sizes, the surface areas of the activated carbon particles increased, thus resulting in greater removal capacities as well as the ability to effectively inject the smaller grained activated carbon into the subsurface. Laboratory and numerical studies for per- and polyfluoroalkyl substances (PFAS) have shown that particle size of the activated carbon can significantly affect the treatment effectiveness and lifespan of activated carbon [4] [5].

Determinations of the presence and distribution of the remedial reagents being injected within the impacted geologic media are rarely completed and reported even though it is recognized that distribution of remedial reagents is one of the key factors for the success of in situ remedial programs. Studies of the distribution of injected reagents are limited and are usually associated with injection programs involving zero-valent iron [6] [7] [8]. These studies have concluded the distribution of the iron is significantly influenced by the heterogeneity of the subsurface. McGregor [9] as part of an injection study for the in situ treatment of PFAS looked at the distribution of injected colloidal activated carbon (CAC) at a silty sand site in Central Canada and concluded that the CAC was effectively distributed within the targeted injection zone using DPT and a dense injection network. A pilot-scale study by McGregor [10] at a sandy aquifer site involving the injection of six different reagents, including CAC, powdered activated carbon (PAC), ion-exchange resin, biochar and the oxidants hydrogen peroxide and sodium persulfate, determined that the particle size of the reagents strongly influenced the distribution of the reagents within the subsurface, which affected the treatment effectiveness of the reagents for the compounds of concern (i.e. PFAS).

This study looks at the distribution of CAC and PAC at four sites with varying 
geology to aid the evaluation of the effects geology and injection methods have on the distribution of the remedial reagents in this study, specifically CAC and PAC.

\section{Site Description}

Four sites were tested using both powdered activated carbon (PAC) and colloidal activated carbon (CAC). Each site was impacted by various compounds of concern with Sites 3 and 4 impacted by petroleum hydrocarbons including benzene, toluene, ethylbenzene and xylenes (BTEX). Site 1 was impacted by PFAS and Site 2 was impacted by chlorinated ethenes including trichloroethene (TCE), cis1,2-dichloroethene (cis1,2-DCE) and vinyl chloride. The geology of the four impacted aquifers ranged from a clean fine sand (Site 1), a glacial till (Site 2), a glacial fluvial deposit (Site 3) and a fine sand with some silt (Site 4). All the sites showed some heterogeneity within the impacted aquifer with thin seams of more conductive material being present within the impacted zone of each aquifer.

The hydrogeology of the sites varied with all aquifers being unconfined. The geometric mean of the horizontal hydraulic conductivity $\left(\mathrm{K}_{\mathrm{H}}\right)$ of each site ranged from $7.2 \times 10^{-2} \mathrm{~m} /$ day (Site 2) to $5.7 \mathrm{~m} /$ day (Site 1 ). The $\mathrm{K}_{\mathrm{H}}$ at Site 1 ranged from $3.6 \mathrm{~m} /$ day to $37 \mathrm{~m} /$ day, whereas the $\mathrm{K}_{\mathrm{H}}$ of the impacted aquifer at Site 2 ranged from $6.8 \times 10^{-3} \mathrm{~m} /$ day to $4.1 \mathrm{~m} /$ day (Figure 1 ). Site 3 had a $\mathrm{K}_{\mathrm{H}}$ geometric mean of $1.1 \mathrm{~m} /$ day ranging from $0.16 \mathrm{~m} /$ day to $48.5 \mathrm{~m} /$ day, whereas Site 4 had a $\mathrm{K}_{\mathrm{H}}$ geometric mean of $4.6 \mathrm{~m} /$ day ranging from $1.0 \mathrm{~m} /$ day to $79.4 \mathrm{~m} /$ day (Figure 1 ). The highest $\mathrm{K}_{\mathrm{H}}$ values measured within each aquifer corresponded to thin coarse-grain layers. When compared again the $\mathrm{K}_{\mathrm{H}}$ of the surrounding aquifer, the $\mathrm{K}_{\mathrm{H}}$ of the coarse-grain layer was approximately 1 to 2 orders of magnitude greater than the surrounding aquifer material. Horizontal groundwater velocities at each site ranged from 0.1 to $100 \mathrm{~m} /$ year with Sites 1 and 3 having estimated groundwater velocities of $6 \mathrm{~m} /$ year whereas Sites 2 and 4 had estimated velocities of approximately 3 and $12 \mathrm{~m}$ /year, respectively.

\section{Methodology}

At each of the four sites, PAC and CAC were injected in test cells measuring approximately 10 meters $(\mathrm{m})$ by $10 \mathrm{~m}$. The cells were situated in areas of the plume with similar geology, hydrogeology, and contaminant mass loading. The objective of the tests was to compare the behavior and distribution of the PAC and CAC within similar geologic environments. The PAC and CAC were injected by DPT on a 3-metre grid, using either a Geoprobe 6820 or 7822 equipped with 0.038- $\mathrm{m}$ diameter hollow rods and a $0.3-\mathrm{m}$ long screened injection tool. The PAC and CAC were injected at a 10-weight percent solution with the exception at Site 3 where the PAC and CAC were injected at a 20 -weight percent solution due to higher contaminant mass loading rates. The injection pressures ranged from 10 to 250 pounds per square inch (psi), with an average injection pressure 


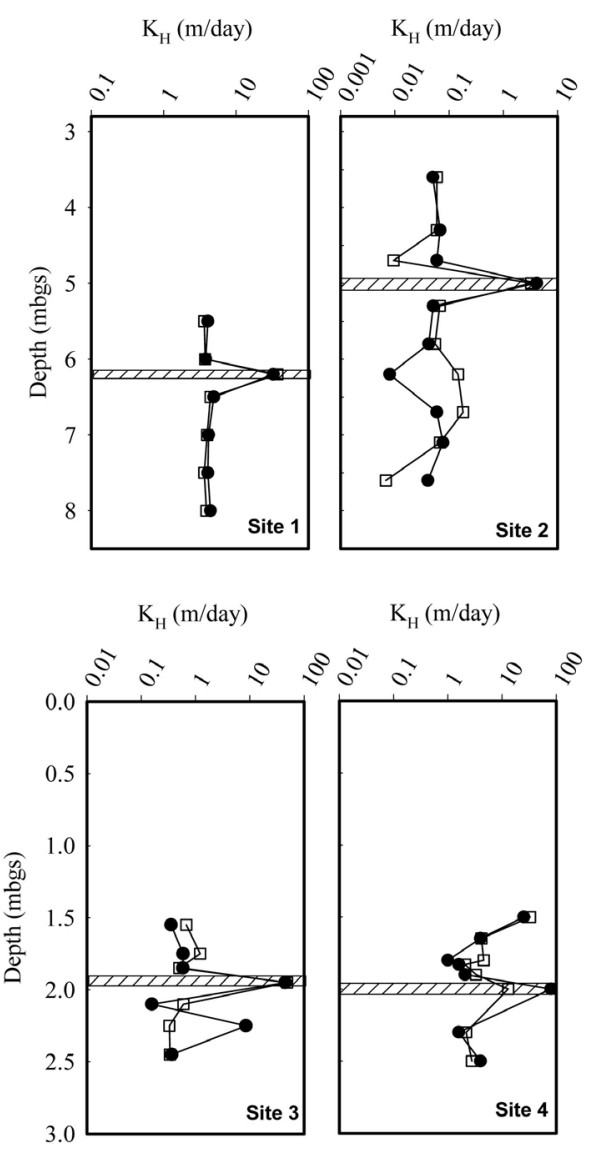

Figure 1. Horizontal hydraulic conductivity $\left(\mathrm{K}_{\mathrm{H}}\right)$ profiles for the 4 test cells. The black circles (O) represent the $\mathrm{K}_{\mathrm{H}}$ measured in the CAC test cells whereas the white squares ( $\square$ ) represent the $K_{H}$ values measured in the PAC test cells. The hatched area represents the interpreted high $\mathrm{K}_{\mathrm{H}}$ seam.

of 36 psi being used to inject the CAC at the four sites compared to an average pressure of 235 psi being required to inject the PAC at the four sites. The PAC and $\mathrm{CAC}$ were injected using a bottom-up technique based on 0.3 -m vertical intervals.

The CAC used in this study was purchased from Regenesis, sold under the brand name PlumeStop ${ }^{\mathrm{Tm}}$, and had a mean diameter of less than $2 \mu \mathrm{m}$ and a specific gravity of up to $1.2 \mathrm{~g} / \mathrm{cm}^{3}$. The PAC injected was Calgon Carbon WPC ${ }^{\mathrm{rm}}$ which had a reported mean grain size of approximately $100 \mu \mathrm{m}$.

Horizontal hydraulic conductivity $\left(\mathrm{K}_{\mathrm{H}}\right)$ estimates were completed using a flexible wall permeameter [11] by collecting continuous cores of the aquifer and subdividing the cores in 0.1 to $0.2 \mathrm{~m}$-long samples. Cores were collected prior to the injection of PAC and CAC to evaluate the heterogeneity of the aquifers. The tests were completed under constant-head conditions using site groundwater.

Prior to testing for $\mathrm{K}_{\mathrm{H}}$, samples of each core were collected for analysis of the total organic carbon (TOC) to determine the organic carbon matter content of the aquifer, prior to the injection of the CAC and PAC. Additional cores of the aquifer were collected 24 hours post injection from each site to determine the 
distribution of the PAC and CAC. Finally, continuous cores of monitoring wellsand packs were collected post-injection to evaluate relative TOC enrichment, if any, of the sand packs surrounding monitoring wells post injection. All aquifer solid samples were collected using continuous coring methods. The aquifer solids were submitted to a commercial laboratory for analysis of TOC using standard laboratory methods [12] [13].

\section{Results and Discussion}

\subsection{Background TOC}

Prior to the injection of the PAC and CAC, measurements were completed to determine the TOC content of the aquifers along with the distribution of organic carbon within the aquifer. The mean background TOC content within the four aquifers ranged from 0.12 weight percent (Site $4, \mathrm{n}=20$, standard deviation $=$ 0.04 weight percent) to 0.16 weight percent (Site $2, \mathrm{n}=34$, standard deviation $=$ 0.08 weight percent), with Sites 1 and 3 having mean TOC values of 0.13 weight percent $(\mathrm{n}=16$, standard deviation $=0.05$ weight percent $)$ and 0.15 weight percent $(n=20$, standard deviation $=0.07$ weight percent), respectively (Figure 2 ).
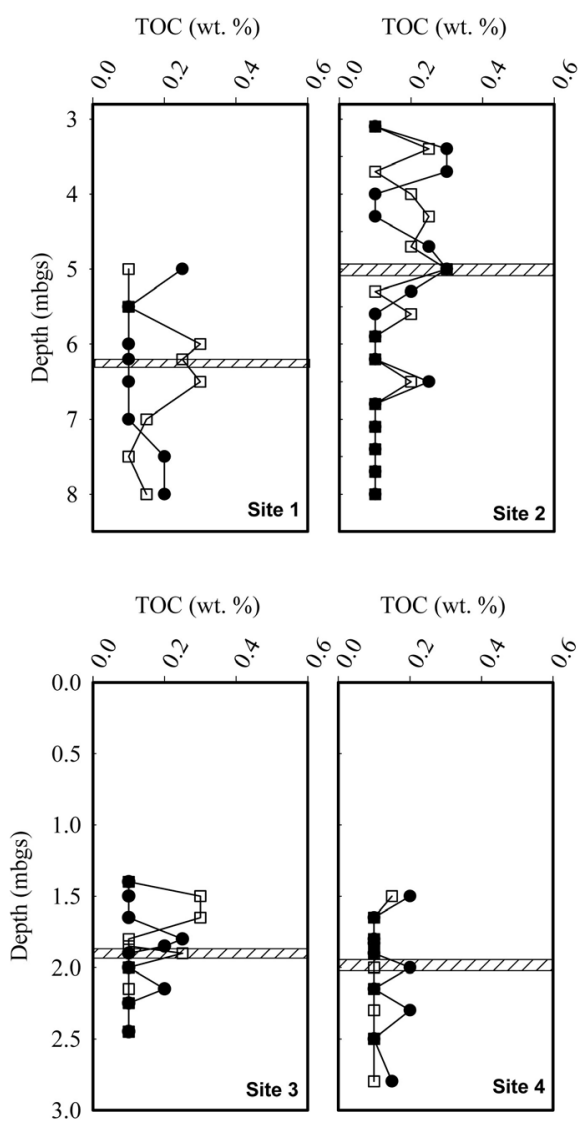

Figure 2. Total organic carbon (TOC) profiles for the 4 test cells prior to the injection of the PAC and CAC. The black circles $(0)$ represent the TOC measured in the CAC test cells whereas the white squares $(\square)$ represent the TOC measured in the PAC test cells. The hatched area represents the interpreted high $\mathrm{K}_{\mathrm{H}}$ seam. 
Comparison of the background TOC between the PAC and CAC test cells within each of the four aquifers determined that the pre-injection TOC showed lateral and vertical variability within the aquifer. The degree of heterogeneity within each aquifer, as measured by TOC, varied with the mean background TOC concentration between the PAC and CAC test cells, varying by up to 29 percent at Site 4 . On average, the background TOC concentration between PAC and CAC test cells within each aquifer varied by 17.5 percent with the pre-injection TOC concentrations varying 22 percent in the Site 1 aquifer, 4 percent in the Site 2 aquifer and 15 percent in the Site 3 aquifer.

\subsection{Radius of Detection}

One of the major design criteria for in situ programs is radius of influence (ROI) which is the basis of the injection grid used to deliver the reagent(s) to the zone of impacts. The ROI generally assumes a uniform radius around an injection point and is developed using a variety of methods ranging from rules of thumb estimates to grids based on pilot testing. Due to subsurface heterogeneities, both laterally and vertically, the ROI used at sites is rarely correct for the whole site. For example, zones of higher $\mathrm{K}_{\mathrm{H}}$ or vertical hydraulic conductivity $\left(\mathrm{K}_{\mathrm{V}}\right)$ within an impacted aquifer can act as preferential pathways when reagents are injected with most of the reagent(s) flowing through these pathways. This preferential flow can lead to poor distribution of the reagent(s) resulting in incomplete treatment of the target compounds of concern. When evaluating the ROI for a site using long-screened monitoring wells observations of reagents within those monitoring wells may provide misleading data on the ROI if a horizontal/semi-horizontal preferential pathway is present within the vertical column of the monitoring well screen. If this situation exists then it is possible that only the higher $\mathrm{K}_{\mathrm{H}}$ portion of the impacted aquifer has been treated with the reagent while the majority of aquifer with a lower $\mathrm{K}_{\mathrm{H}}$ has been left untreated, thus providing an overestimate of the ROI. Based on these challenges, the term radius of detection (ROD) is used in the remainder of this paper as it better reflects the actual lateral distribution of the PAC and CAC within the targeted aquifer.

To estimate if the physical properties of a reagent effected the estimated ROD at each of the four sites, cores of the aquifer were collected at specific distances from a point of injection. The cores were collected down gradient of the point of injection with points located on the furthest down gradient grid being used to minimize possible effects from injections at other up and side gradient injection locations.

Overall, the ROD for the PAC and CAC were at least $7 \mathrm{~m}$ with PAC or CAC being detected in at least one sample collected from cores at this distance (Figure 3). However, at all four sites the peak concentration of TOC within the aquifer samples collected was greater for the PAC samples than the CAC samples (Figure 3). Within the targeted injection zone, the mean TOC concentration for the PAC samples collected at $7 \mathrm{~m}$ from the injection point ranged from 

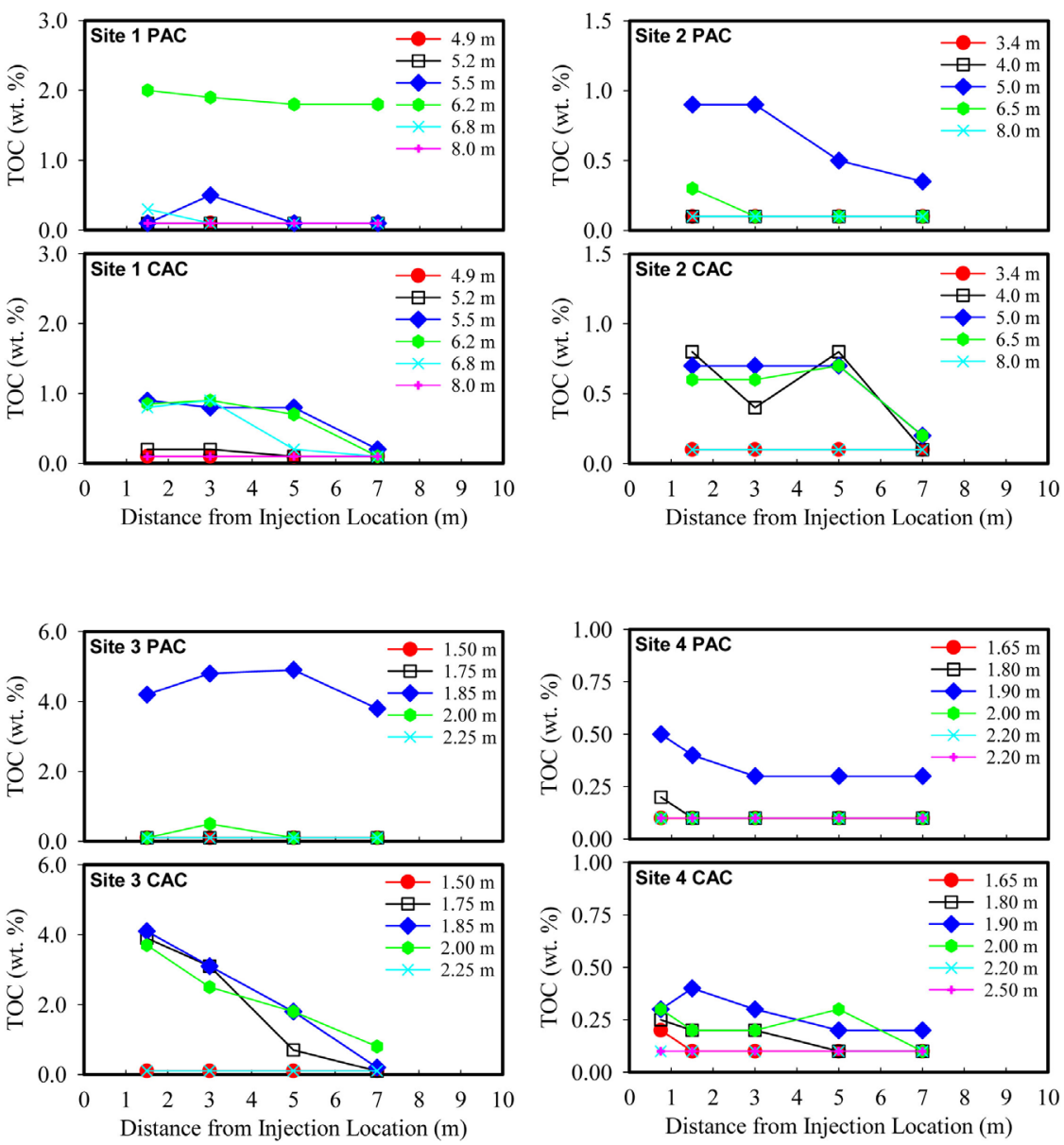

Figure 3. Total organic carbon (TOC) concentrations with distance from injection point for the 4 test cells.

0.17 weight percent at Site 4 to 1.33 weight percent at Site 2. Sites 1 and 3 had mean TOC concentrations of 0.67 weight percent and 0.18 weight percent, respectively. Within the CAC test cells, the mean TOC concentration for aquifer samples collected within the targeted injection zones ranged from 0.13 weight percent at Sites 1 and 4 to 0.37 weight percent at Site 2. Site 3 had a mean TOC concentration of 0.17 weight percent within the targeted injection zone.

When the results of the TOC analysis from each of the four paired PAC-CAC test cells are compared, the mean PAC concentration at a distance of 7 meters from the point of injection ranges from 9.6 percent greater at Site 3 to 415 percent greater at Site 1, and on average 177 percent greater than the TOC concentration at the same distance within the CAC test cells.

\subsection{PAC and CAC Distribution}

A key factor in achieving effective in situ treatment is the distribution of the reagents within the target injection zone. Ideally, the reagents should be distributed evenly throughout the target impacted zone while minimizing the placement of reagents outside of the target impacted zone. In hydrogeologic envi- 
ronments that have low to moderate groundwater velocities, such as the four study sites, reagents are primarily distributed during the injection of the solution and not by subsequent advection/dispersion processes. Advection and dispersion can aid in the distribution of some of the more persistent and fine-grained reagents such as CAC. However, these processes are usually limited and are generally not relied on to distribute reagents at most field sites including the four sites in this study.

To evaluate the distribution of the reagents, continuous soil cores were collected at each site over the depth of the targeted injection zone and analyzed for TOC. Within the eight test cells (four PAC and four CAC), a total of 520 samples were collected with 288 samples being collected within the targeted injection zones and 232 samples were collected above and below the target injection zones. Overall, samples collected within the targeted injection zones of the PAC and CAC test cells had a TOC detection rate of 42.4 percent (standard deviation $=0.78$ eight percent, $\mathrm{n}=144$ ) and 94.4 percent $($ standard deviation $=0.44$ weight percent, $n=144$ ), respectively. Samples collected immediately outside of the targeted injection zones within the PAC and CAC test cells had TOC detection rates of 2.6 percent (standard deviation $=0.02$ weight percent, $\mathrm{n}=116$ ) and 6.9 percent (standard deviation $=0.03$ weight percent, $\mathrm{n}=116$ ), respectively. These results suggest that the majority of $\mathrm{PAC}$ and $\mathrm{CAC}$ injected during the tests were delivered to the targeted injection zones. However, the distribution of CAC was more uniform than the distribution of PAC within the targeted injection zones as discussed below

\subsubsection{PAC Test Cells}

Examination of the TOC detection rates within each test cell indicated that the TOC detection rate within the PAC cells ranged from 28.6 percent at Site 2 to 66.7 percent at Site 1. Sites 3 and 4 had TOC detection rates of 46.7 percent and 41.9 percent, respectively. The majority of samples with TOC concentrations greater than the method detection limit of 0.10 weight percent (50.8 percent), were collected within the thin layers of aquifer material that had a higher $\mathrm{K}_{\mathrm{H}}$ value compared to the surrounding aquifer material. When the mean of the TOC concentration of the samples collected within the higher $\mathrm{K}_{\mathrm{H}}$ layers are compared against the surrounding TOC concentration of the aquifer materials within the targeted injection zones of the four PAC test cells, the TOC concentration is on average 994 percent greater, ranging from 209 percent at Site 4 to 2880 percent at Site 3.

TOC concentrations within the PAC targeted injection zone at Site 1 averaged 0.78 weight percent (standard deviation $=0.79$ weight percent, $\mathrm{n}=27$ ) compared to a mean TOC concentration of 0.12 weight percent outside of the targeted injection zone. The TOC concentration varied with depth from below the analytical detection limit of 0.10 weight percent to 2.5 weight percent (Figure 4). Within the PAC targeted injection zone 66.7 percent of the samples analyzed ( $\mathrm{n}$ $=27)$ had concentrations of TOC greater than the method detection limit of 0.10 

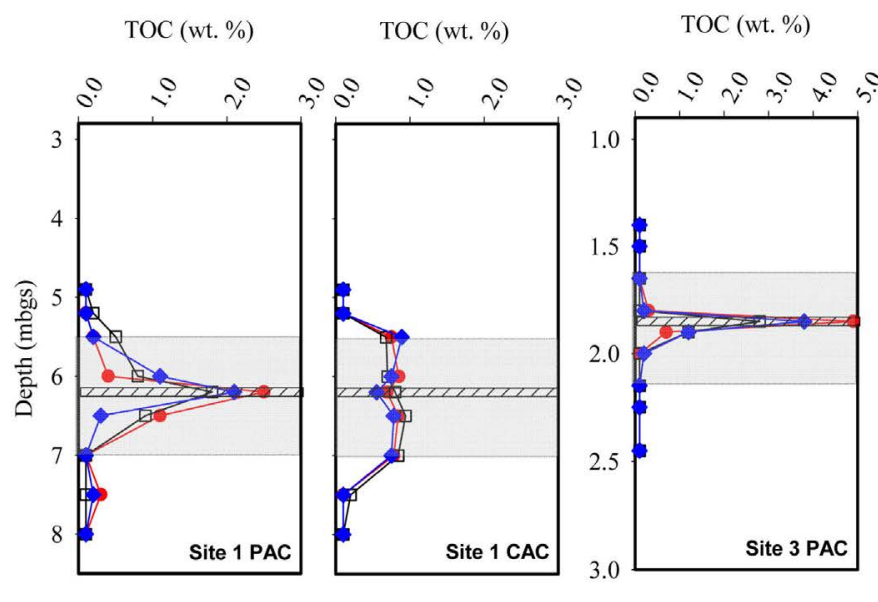

TOC (wt. \%)

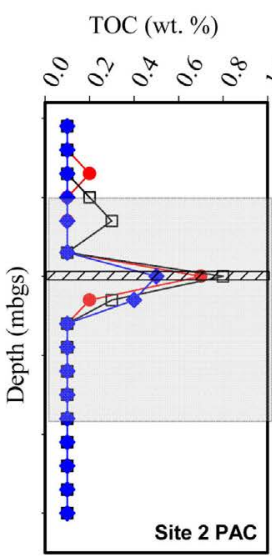

TOC (wt. \%)
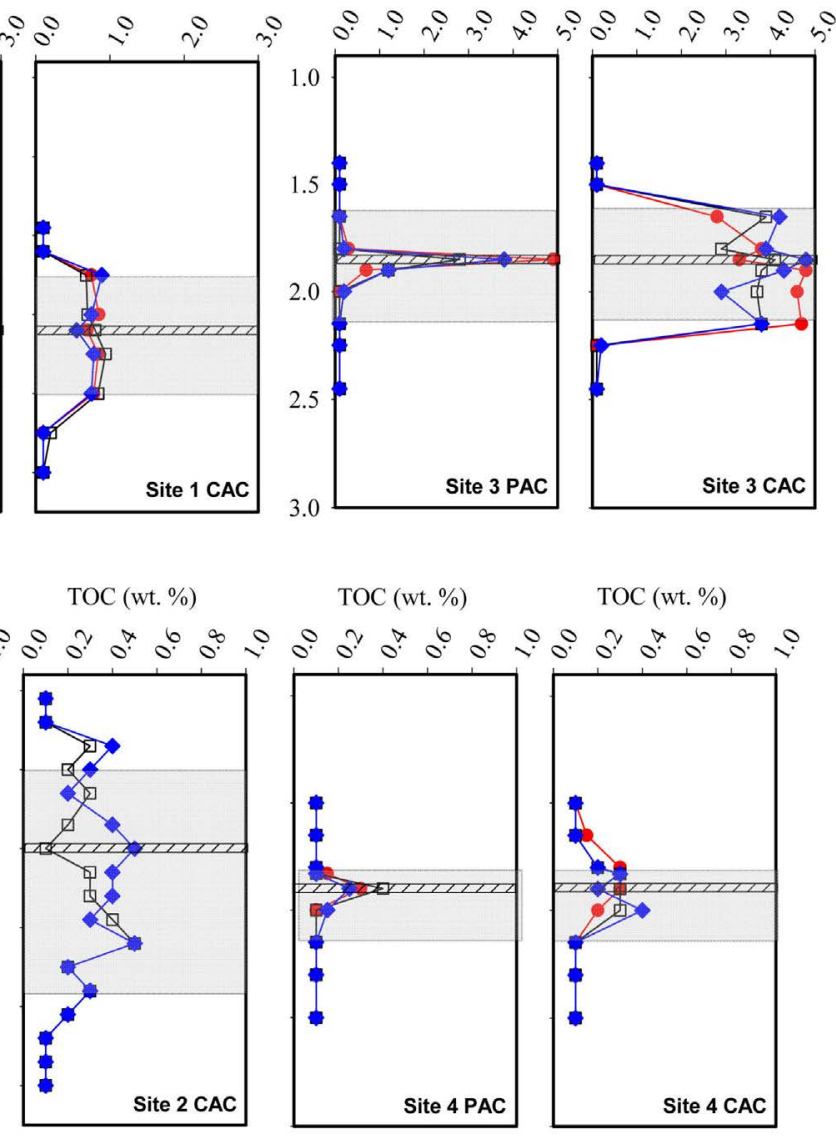

TOC (wt. \%)

Figure 4. Total organic carbon (TOC) profiles for the 4 test cells following the injection of the PAC and CAC. The red circles $(0)$ represent the TOC results from Core 1, the white squares $(\square)$ represent the TOC results from Core 2 and the blue rhombus $(\diamond)$ are the results from Core 3. The hatched area represents the interpreted high $\mathrm{K}_{\mathrm{H}}$ seam and the shaded area represents the targeted zone of injection.

weight percent with the seven greatest TOC concentrations being measured within the high $\mathrm{K}_{\mathrm{H}}$ layer located at 6.2 meters below ground surface (mbgs). Outside of the PAC targeted injection zone, 12.5 percent of the samples analyzed had detectable concentrations of TOC $(n=12)$. The pre-injection TOC concentration within the targeted injection zone was 0.11 weight percent (standard deviation $=0.002$ weight percent, $\mathrm{n}=10$ ), whereas post injection the mean TOC concentration within the samples collected from the targeted injection zone was 0.78 weight percent (standard deviation $=0.79, \mathrm{n}=27$ ), representing a TOC concentration increase of 610 percent.

At Site 2, the post-injection aquifer solid TOC concentrations within the PAC targeted injection zone averaged 0.21 weight percent (standard deviation $=0.22$ weight percent, $\mathrm{n}=56$ ) compared to an average pre-injection TOC concentration of 0.16 weight percent (standard deviation $=0.09$ weight percent, $n=17$ ). This represents a 30 percent increase on average for TOC concentrations within the PAC targeted injection zone. As with Site 1, the TOC concentration varied 
with depth at Site 2 with TOC concentrations ranging from the analytical detection limit of 0.10 weight percent to 0.80 weight percent (Figure 4). Within the PAC targeted injection zone 28.6 percent of the samples analyzed $(n=56)$ had concentrations of TOC greater than the method detection limit of 0.10 weight percent. The highest TOC concentrations were measured within the high $\mathrm{K}_{\mathrm{H}}$ layer located at a depth of approximately $5.0 \mathrm{mbgs}$ (Figure 4). Outside of the targeted injection zone, TOC was not detected at concentrations greater than the analytical method detection limit of 0.10 weight percent (Figure 4).

Total organic carbon concentrations within the aquifer solids collected from the PAC test cell at Site 3 determined that 46.7 percent of the samples had TOC concentrations greater than the method detection limit of 0.10 weight percent, with concentrations ranging from 0.10 weight percent to 4.9 weight percent within the high $\mathrm{K}_{\mathrm{H}}$ seam located at approximately 1.85 mbgs (Figure 4). The mean TOC concentration within the aquifer solids collected within the targeted injection zone increased by 736 percent, with the mean post injection TOC concentration determined to be 1.17 weight percent (standard deviation $=1.8$ weight percent, $\mathrm{n}=30$ ) compared to a pre-injection TOC mean concentration of 0.14 weight percent (standard deviation $=0.06$ weight percent, $\mathrm{n}=10$ ). Like Site 2, the TOC concentrations at Site 3 outside of the targeted injection zone post injection were below the analytical method detection limit of 0.10 weight percent (Figure 4).

Additional soil sampling of the aquifer was completed at Site 3 to determine the distribution of the PAC in a three-dimensional view (Figure 5). The results of the sampling further enhanced the conclusion derived from the above sampling, clearly illustrating that the high $\mathrm{K}_{\mathrm{H}}$ seam that is present at $1.85 \mathrm{mbgs}$ is the dominant pathway for the delivery of the PAC at this site. Aquifer samples collected within the targeted injection zone at $1.70 \mathrm{mbgs}$ and $2.10 \mathrm{mbgs}$ had a TOC detection rate of 25 percent, indicating that the PAC was preferentially delivered to the high $\mathrm{K}_{\mathrm{H}}$ seam within the targeted injection zone (Figure 5).

The TOC concentrations collected within the targeted injection zone post injection at Site 4 averaged 0.18 weight percent (standard deviation $=0.12$ weight percent, $\mathrm{n}=31$ ) compared to an average pre-injection TOC concentration of 0.14 weight percent (standard deviation $=0.05$ weight percent, $\mathrm{n}=10$ ). This represents a 33 percent increase on average for the TOC within the targeted injection zone at Site 4 . The TOC concentration varied with depth, from below the analytical detection limit of 0.10 weight percent to 0.40 weight percent (Figure 4). Within the targeted injection zone 41.9 percent of the samples analyzed ( $\mathrm{n}=$ 31) had concentrations of TOC greater than the method detection limit of 0.1 weight percent. As with the other three PAC test cells, the greatest TOC concentrations were measured within the high $\mathrm{K}_{\mathrm{H}}$ layer located within the test cell (Figure 4). Outside of the targeted injection zone, none of the TOC concentrations were detected at concentrations greater than the analytical method detection limit of 0.10 weight percent (Figure 4). 

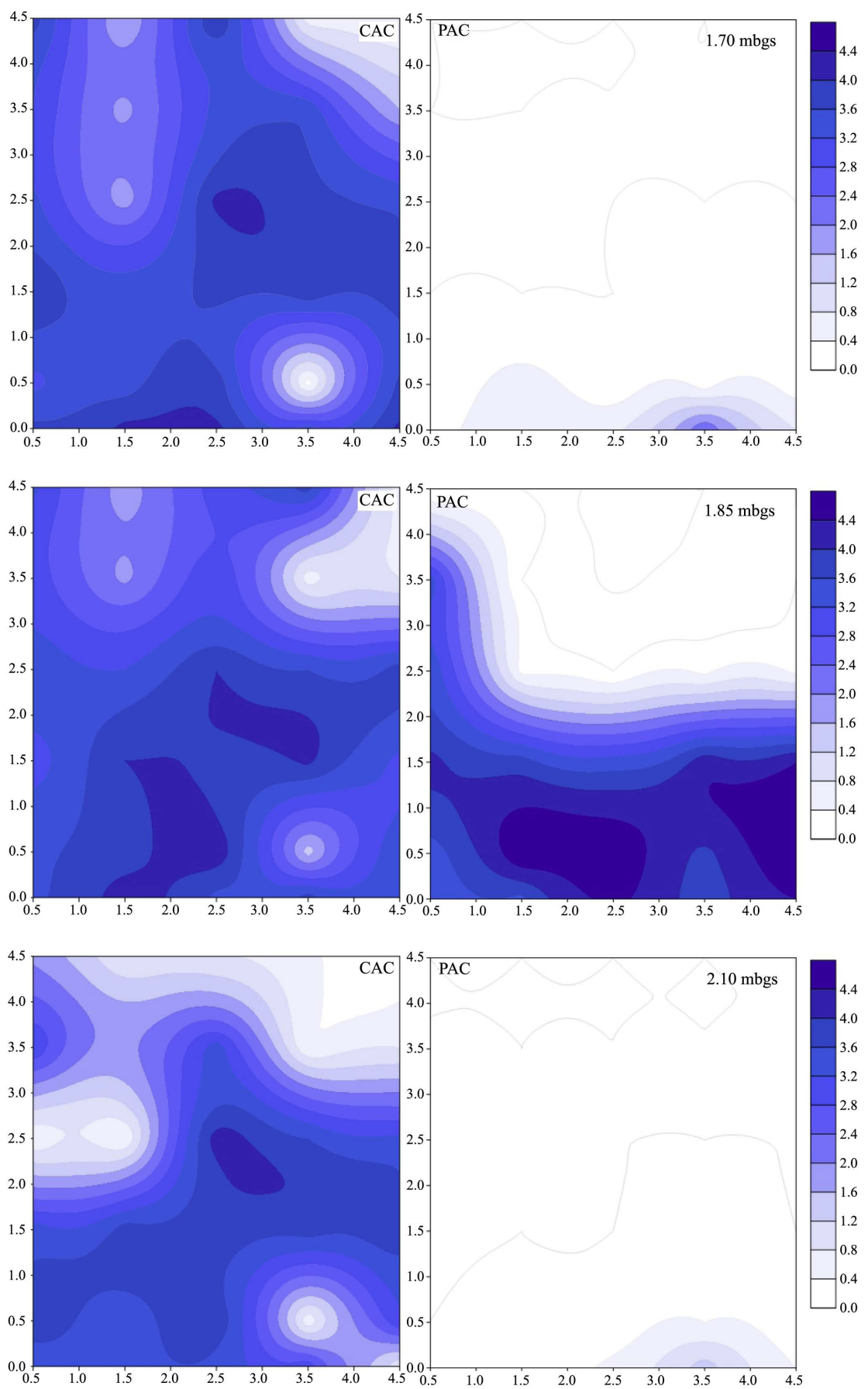

Figure 5. Total organic carbon (TOC) plots for the PAC and CAC test cells at Site 3 following the injection of the CAC and PAC at various depths (1.70, 1.85 and $2.10 \mathrm{mbgs}$ ). The grid is in meters and concentration scale is in weight percent. The high $\mathrm{K}_{\mathrm{H}}$ zone is located at 1.85 mbgs.

\subsubsection{CAC Test Cells}

Total organic carbon detection rates within the targeted injection zones for the four CAC test cells were all greater than 90 percent, ranging from 90.3 percent at Site 4 to 96.7 percent at Site 3. Sites 1 and 2 had TOC detection rates of 92.6 percent and 96.7 percent, respectively. Unlike the distribution of TOC within the 
PAC test cells, the TOC within the CAC test cells was more uniformly distributed including when comparing the TOC within the high $\mathrm{K}_{\mathrm{H}}$ zones and the surrounding material within the targeted injection zone. The mean TOC concentrations within the high $\mathrm{K}_{\mathrm{H}}$ zone ranged from less than 8.0 percent (Site 1) to greater than 32.1 percent (Site 2) greater than the surrounding mean compared to the mean TOC concentrations of the surrounding aquifer materials within the targeted injection zones. These TOC values, when compared to the PAC test cells, suggest that the CAC was more uniformly distributed than the PAC and not as susceptible to the preferential pathway created by the high $\mathrm{K}_{\mathrm{H}}$ seam.

Evaluation of the individual CAC test cells indicate that the TOC concentrations within the targeted injection zone at Site 1 averaged 0.75 weight percent (standard deviation $=0.16$ weight percent, $\mathrm{n}=27$ ), compared to an average TOC concentration of 0.11 weight percent (standard deviation $=0.03$ weight percent, $\mathrm{n}=24$ ) outside of the targeted injection zone. The TOC concentration varied, with depth from below the analytical detection limit of 0.10 weight percent to 2.5 weight percent (Figure 4), with the lowest TOC values being measured at seven meters from the injection point. All the samples collected within five meters of the injection point had detectable TOC concentrations. Within the targeted injection zone, 92.6 percent of the samples analyzed $(n=27)$ had concentrations of TOC greater than the method detection limit of 0.10 weight percent. The seven samples collected within the high $\mathrm{K}_{\mathrm{H}}$ layer located at $6.2 \mathrm{mbgs}$ having a mean TOC concentration of 0.66 weight percent compared to a TOC mean of 0.71 weight percent for samples collected within the surrounding targeted injection zone. Outside of the targeted injection zone, 12.5 percent of the samples analyzed had detectable concentrations of TOC $(\mathrm{n}=24)$. The pre-injection TOC concentration within the targeted injection zone was 0.11 weight percent (standard deviation $=0.02$ weight percent, $\mathrm{n}=8$ ) representing a TOC concentration increase of 582 percent.

Aquifer samples analyzed for TOC collected within the targeted injection zone at Site 2 averaged 0.37 weight percent (standard deviation $=0.17$ weight percent, $\mathrm{n}=56$ ) compared to an average pre-injection TOC concentration of 0.15 weight percent (standard deviation $=0.07$ weight percent, $\mathrm{n}=17$ ). This represents a 147 percent increase on average for the TOC within the targeted injection zone. The TOC concentration varied with depth, with TOC concentrations ranging from the analytical detection limit to 0.80 weight percent (Figure 4). Within the targeted injection zone, 96.4 percent of the samples analyzed $(n=56)$ had concentrations of TOC greater than the method detection limit. The TOC concentrations measured within the high $\mathrm{K}_{\mathrm{H}}$ layer located at a depth of approximately 5.0 mbgs averaged 0.46 weight percent compared to the mean TOC concentration of 0.35 weight percent for the samples collected within the targeted injection zone excluding the high $\mathrm{K}_{\mathrm{H}}$ layer samples (Figure 4). Outside of the targeted injection zone, the mean TOC concentration was 0.11 weight percent (standard deviation $=0.03$ weight percent, $\mathrm{n}=32$ ) with 6.3 percent of the samples having TOC concentrations greater than the analytical method detection limit (Figure 4). 
Total organic carbon concentrations measured in the aquifer solids collected from CAC test cell at Site 3 determined that 96.7 percent of the samples had TOC concentrations greater than the method detection limit, with concentrations ranging from 0.10 weight percent to 4.8 weight percent (Figure 4). Comparison of the TOC concentrations from samples collected from the high $\mathrm{K}_{\mathrm{H}}$ seam and those surrounding the high $\mathrm{K}_{\mathrm{H}}$ seam within the targeted injection zone indicated that the high $\mathrm{K}_{\mathrm{H}}$ seam had a mean TOC concentration of 3.1 weight percent, compared to a mean TOC concentration of 3.2 weight percent for the surrounding samples.

The mean TOC concentration of the aquifer solids collected within the targeted injection zone increased by 1965 percent with the mean post injection TOC being determined to be 3.2 weight percent (standard deviation $=1.3$ weight percent, $\mathrm{n}=30$ ) compared to a pre-injection TOC mean concentration of 0.16 weight percent (standard deviation $=0.09$ weight percent, $\mathrm{n}=10$ ). The TOC concentrations outside of the targeted injection zone post injection ranged from below the analytical method detection limit of 0.10 weight percent to 0.2 weight percent, averaging 0.11 weight percent (standard deviation $=0.02$ weight percent, $\mathrm{n}=20$ ) (Figure 4).

As with the PAC test cell, additional soil sampling of the aquifer was completed at Site 3 to determine the distribution of the CAC in a three-dimensional view (Figure 5). The results of the sampling suggest that the CAC was relatively well distributed within five meters of the injection point, with TOC being detected within the aquifers solids at a rate of 100 percent $(n=90)$. The mean TOC concentration of the samples collected within the high $\mathrm{K}_{\mathrm{H}}$ seam that is present at 1.85 mbgs was 3.1 weight percent (standard deviation $=1.1$ weight percent, $\mathrm{n}=$ 30) compared to 2.8 weight percent (standard deviation $=1.3$ weight percent, $n$ $=60$ ) for the remaining samples analyzed above and below the seam (Figure 5).

At Site 4, the TOC concentrations within the targeted injection zone averaged 0.25 weight percent (standard deviation $=0.08$ weight percent, $\mathrm{n}=31$ ) compared to an average pre-injection TOC concentration of 0.11 weight percent (standard deviation $=0.02$ weight percent, $\mathrm{n}=10$ ). This represents a 127 percent increase on average for the TOC within the targeted injection zone. The TOC concentration varied, with depth from below the analytical detection limit of 0.10 weight percent for some samples collected at least $5 \mathrm{~m}$ away from the point of injection to 0.40 weight percent (Figure 4). Within the targeted injection zone, 90.3 percent of the samples analyzed $(n=31)$ had concentrations of TOC greater than the method detection limit of 0.10 weight percent. The TOC concentrations for samples collected with the high $\mathrm{K}_{\mathrm{H}}$ layer averaged 0.28 weight percent compared to 0.24 weight percent for samples collected elsewhere within the targeted injection zone (Figure 4). The TOC concentrations outside of the targeted injection zone post injection ranged from below the analytical method detection limit of 0.10 weight percent to 0.15 weight percent, averaging 0.10 weight percent (standard deviation $=0.02$ weight percent, $\mathrm{n}=40$ ) (Figure 4). 


\subsection{PAC and CAC Distribution within Wellsand Packs}

Previous studies by others [10] [14] indicated that there could be preferential accumulation of PAC within pre-existing monitoring wellsand packs following the injection of the PAC. This preferential accumulation of PAC in monitoring wellsand packs could result in non-representative groundwater samples being collected and used for the evaluation of remedial activities.

To evaluate if this preferential accumulation was occurring within the eight test cells, continuous cores of the monitoring wellsand packs were collected and analyzed for TOC. The results of the analysis suggest that preferential accumulation occurred within the PAC monitoring wellsand packs during the injection of the coarser-grained reagent, with an average TOC concentration of 1.65 weight percent being determined in the four PAC cell monitoring wellsand packs. Of the 16 samples collected from the PAC monitoring wellsand packs within the PAC test cells, 94 percent had TOC concentrations greater than the analytical detection limit of 0.10 weight percent (Figure 6). The TOC concentrations for the PAC monitoring wellsand packs were 224 percent greater than the mean TOC concentration within surrounding targeted injection zone. The analyses of the TOC content within the sand packs for the PAC test cells also showed TOC enrichment of the sand pack above and below the targeted injection zone suggesting that the sand pack was acting as a vertical conduit for the migration of the PAC during injection activities (Figure 6).

Like the PAC monitoring wellsand packs, TOC was detected within 81 percent of samples collected from the four CAC pre-existing monitoring wellsand packs $(n=16)$, with a mean TOC concentration of 0.65 weight percent. This is 35 percent less than the mean TOC concentration for the samples collected within the surrounding targeted injection zone. These results suggest that while TOC was present within the sand packs of the monitoring wells installed prior to

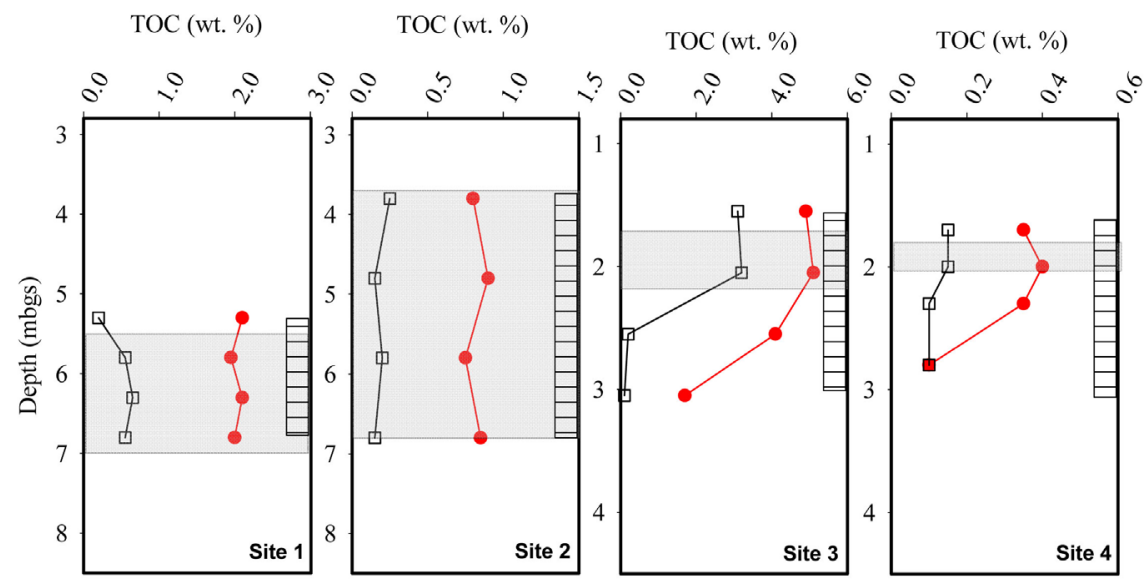

Figure 6. Total organic carbon (TOC) profiles for the monitoring wellsand packs sampled in the 4 test cells following the injection of the PAC and CAC. The red circles (O) represent the TOC results for the PAC test cells and the white squares ( $\square$ ) represent the TOC results from the CAC test cells. The hatched area represents the well screen and the shaded area represents the targeted zone of injection. 
the injection of the CAC, the CAC did not preferentially accumulate within the sand pack; unlike the PAC which showed an enrichment relative to the surrounding aquifer material.

\section{Conclusions}

Four pilot tests were conducted in four geological different unconfined aquifers to evaluate the effect of heterogeneity on the distribution of PAC and CAC within impacted aquifers. Overall, the injection of PAC and CAC increased the mean TOC concentration within the targeted injection zones for the aquifers by 244 percent and 590 percent, respectively. This overall increase in the TOC of the aquifer will lead to increased retardation rates for a wide variety of organic and potentially some inorganic compounds of concern through adsorption and absorption reactions.

Determinations of the $\mathrm{K}_{\mathrm{H}}$ indicated that all four sites had significant heterogeneities within the targeted injection zones with the $\mathrm{K}_{\mathrm{H}}$, varying by at least one order of magnitude and up to two orders of magnitude over less than $0.1 \mathrm{~m}$ vertical spacing. This heterogeneity had a significant impact on the distribution of the coarser-grained PAC at all four test sites. Comparison of the mean TOC concentrations within the high $\mathrm{K}_{\mathrm{H}}$ seams versus the mean TOC concentration in the surrounding aquifer material targeted by the injection at the four PAC test cells indicated that on average the TOC concentration within the high $\mathrm{K}_{\mathrm{H}}$ seams was 994 percent greater than the surrounding aquifer materials within the targeted injection zones. Similar comparisons for the four CAC test cells suggest that the TOC concentration of the aquifer materials sampled from the high $\mathrm{K}_{\mathrm{H}}$ seams within the targeted injection zones ranged from -8.0 percent to 32.1 percent greater than the surrounding mean TOC concentrations within the remainder of the targeted injection zones. These values, when compared to the PAC test cells, suggest that the CAC was more uniformly distributed than the PAC and not as susceptible to the preferential pathway created by the high $\mathrm{K}_{\mathrm{H}}$ seam as was the PAC.

The presence of the high $\mathrm{K}_{\mathrm{H}}$ seams within the PAC test cells also influenced the overall distribution of the PAC with TOC being detected within 28.6 percent to 66.7 percent of the samples collected from the targeted injection zones, compared to all of the CAC test cells having at least 90.3 percent of the samples being collected from the targeted injection zones having detectable TOC concentrations. Measurements of the TOC content within the four aquifers with distance from the point of injection determined that both the PAC and CAC were detected at distances of at least seven $\mathrm{m}$ from the point of injection, with PAC concentrations being on average higher than the CAC with distance. The distribution of the PAC with distance was heavily influenced by the presence of high $\mathrm{K}_{\mathrm{H}}$ seams, with the majority of TOC detections being made within the high $\mathrm{K}_{\mathrm{H}}$ seams whereas for the CAC test cells, the TOC was more uniformly distributed over the targeted injection zones. 
Prior to the injection of the PAC and CAC, measurements of the TOC were completed to determine the TOC content of the aquifers along with the distribution of organic carbon within the aquifer. The mean background TOC content within the four aquifers ranged from 0.12 weight percent (Site $4, \mathrm{n}=20$, standard deviation $=0.04$ weight percent) to 0.16 weight percent (Site $2, \mathrm{n}=34$, standard deviation $=0.08$ weight percent), with Sites 1 and 3 having mean TOC values of 0.13 weight percent $(n=16$, standard deviation $=0.05$ weight percent) and 0.15 weight percent $(n=20$, standard deviation $=0.07$ weight percent $)$, respectively.

Sampling of monitoring wellsand packs post-injection suggested that both the PAC and CAC could accumulate within the sand packs of monitoring wells installed prior to the injection of the PAC and CAC. Analysis of the sand pack material indicated that the monitoring wells installed within the PAC test cells were highly susceptible to the accumulation of PAC, with a 224 percent increase in the mean concentration of TOC compared to the surrounding target injection zone. The sand packs within the CAC test cells had a mean TOC concentration of 0.65 weight percent which was a 35 percent decrease in TOC concentration compared to the surrounding TOC concentration measured within the four CAC targeted injection zones. These results suggest that consideration be given to installing new monitoring wells post-injection at both CAC and PAC injected sites to ensure representative groundwater samples are used in the evaluation of CAC and PAC treated sites. This recommendation is especially applicable to PAC-injected sites with similar geologies as tested in this study.

\section{Acknowledgements}

The author would like to acknowledge Adria Keleher, and two anonymous reviewers for their editorial comments, which greatly improved the quality of the paper.

\section{Conflicts of Interest}

The author declares no conflicts of interest regarding the publication of this paper.

\section{References}

[1] United States Environmental Protection Agency (2017) Superfund Remedy Report. 15th Edition, EPA, Colombia, 1-165.

[2] Interstate Technology \& Regulatory Council (ITRC) (2005) Technical and Regulatory Guideline for in Situ Chemical Oxidation of Contaminated Soil and Groundwater. 2nd Edition, Interstate Technology \& Regulatory Council in Situ Chemical Oxidation Team, Washington DC.

[3] Rosansky, S., Condit, W. and Sirabian, R. (2013) Best Practices for Injection and Distribution of Amendments. Naval Facilities Engineering Command (NAVFAC), $81 \mathrm{p}$.

[4] Carey, G.R. and McGregor, R. (2019) Evaluating the Longevity of a PFAS in Situ 
Colloidal Activated Carbon Remedy. Remediation, 29, 17-31. https://doi.org/10.1002/rem.21593

[5] Xiao, X., Ulrich, B.A., Chen, B. and Higgins, C.P. (2017) Sorption of Poly- and Perfluoroalkyl Substances (PFASs) Relevant to Aqueous Film-Forming Foam (AFFF) Impacted Groundwater by Biochars and Activated Carbon. Environmental Science \& Technology, 51, 6342-6351. https://doi.org/10.1021/acs.est.7b00970

[6] Buchau, A., Rucker, W.M., de Boer, C.V. and Klaas, N. (2010) Inductive Detection and Concentration Measurement of Nano Sized Zero Valent Iron in the Subsurface. IET Science, Measurement, and Technology, 4, 289-297. https://doi.org/10.1049/iet-smt.2009.0016

[7] Dalla Vecchia, E., Luna, M. and Sethi, R. (2009) Transport in Porous Media of Highly Concentrated Iron Micro- and Nanoparticles in the Presence of Xanthan gum. Environmental Science \& Technology, 43, 8942-8947. https://doi.org/10.1021/es901897d

[8] Christiansen, C.M., Riis, C., Christensen, C.B., Broholm, M.M., Christensen, A.G., Klint, K.E.S., Wood, J.S.A., Bauer-Gottwein, P. and Bjerg, P.L. (2008) Characterization and Quantification of Pneumatic Fracturing Effects at a Clay Till Site. Environmental Science \& Technology, 42, 570-576. https://doi.org/10.1021/es071294s

[9] McGregor, R. (2018) In Situ Treatment of PFAS-Impacted Groundwater Using Colloidal Activated Carbon. Remediation, 28, 33-41.

https://doi.org/10.1002/rem.21558

[10] McGregor, R. (2020) Six Pilot-Scale Studies Evaluating the in Situ Treatment of PFAS in Groundwater. Remediation, 30, 39-50. https://doi.org/10.1002/rem.21653

[11] American Society for Testing Methods (2016) Standard Test Methods for Measurement of Hydraulic Conductivity of Saturated Porous Materials Using a Flexible Wall Permeameter. West Conshohocken, WA.

[12] American Society for Testing Methods (2011) Standard Test Methods for Determination of Carbon, Sulfur, Nitrogen, and Oxygen in Steel, Iron, Nickel, and Cobalt Alloys by Various Combustion Fusion Techniques. West Conshohocken, WA.

[13] American Society for Testing Methods (2013) Standard Test Methods for Determination of Oxygen and Nitrogen in Titanium and Titanium Alloys by Inert Gas Fusion. West Conshohocken, WA.

[14] Fan, D., Gilbert, E.J. and Fox, T. (2017) Current State of in Situ Subsurface Remediation by Activated Carbon Based Amendments. Journal of Environmental Management, 204, 1-11. https://doi.org/10.1016/j.jenvman.2017.02.014 